Article

\title{
Correlation between Tensile Deformation Behavior and Microstructural Morphology of Nuclear Grade Austenitic Stainless Steel Welded Joints using Infrared Thermography Technique
}

\author{
R. Rajasekaran ${ }^{1}$, A.K. Lakshminarayanan ${ }^{1}$ and M. Menaka ${ }^{2}$ \\ ${ }^{1}$ Department of Mechanical Engineering, SSN College of Engineering, Tamil Nadu, 603110 India \\ Mr. R. Rajasekaran; rajasekaranr@ssn.edu.in; \\ 2 Indira Gandhi Centre for Atomic Research (IGCAR), Kalpakkam, Tamil Nadu, 603103 India \\ M. Menaka, Ph.D.; menaka@igcar.gov.in; \\ * Correspondence: Prof. A.K. Lakshminarayanan, Ph.D.; lakshminarayananak@ssn.edu.in
}

Received: 02.12.2019; Accepted: 24.01.2020

\begin{abstract}
Tensile deformation behavior of nuclear grade Austenitic Stainless Steel (SS) and its welded joints fabricated by Gas Tungsten Arc Welding (GTAW) and Activated Flux Gas Tungsten Arc Welding (AGTAW) processes were studied and correlated with relevant microstructural morphologies using Infrared Thermography (IRT) technique. The microstructure of base metal showed a complete austenite phase. GTAW Fusion Zone (FZ) exhibited both primary ferrite and primary austenite mode of solidification. Meantime, AGTAW FZ exhibited only primary austenite mode of solidification. A strain rate of $4.4 \times 10^{-4} \mathrm{~s}^{-1}$ was used during the tensile test of the base metal and welded joints. The failure locations of the base metal, GTAW and AGTAW samples were noticed at the center of the gauge portion, the base metal side away from Fusion Line (FL) and Heat Affected Zone (HAZ) respectively. The temperature variations of the base metal and weld zones were recorded in the form of thermograms using the IR camera at the different stages of the tensile deformation. During deformation study, peak temperature of $39.2{ }^{\circ} \mathrm{C}, 38.8^{\circ} \mathrm{C}$ and $34^{\circ} \mathrm{C}$ were observed at the base metal, GTAW and AGTAW samples respectively. The lesser peak temperature of the AGTAW sample compared to the base metal and GTAW samples indicated that the AGTAW sample undergone lesser deformation. Moreover, tensile deformation behaviours of the base metal and welded joints were correlated with their microstructural morphologies using corresponding temperature curves.
\end{abstract}

Keywords: Infrared Thermography (IRT); Activated flux Gas Tungsten Arc Welding (AGTAW); 316LN austenitic stainless steel; strain rate; thermoelastic effect; plastic deformation

\section{Introduction}

The 316LN austenitic stainless steel is used as a significant structural material for the fabrication of nuclear reactors due to its good mechanical and corrosion resistance properties at high temperatures [1]. Currently, the joining of 316LN SS together is done using the Gas Tungsten Arc Welding (GTAW) process. The lack of weld pool penetration depth is the main drawback of the GTAW process. The achievement of the higher depth of penetration between SS plates was proved by some researchers by introducing active chemical elements (metal oxides such as $\mathrm{SiO}_{2}, \mathrm{TiO}_{2}, \mathrm{Fe}_{2} \mathrm{O}_{3}, \mathrm{Cr}_{2} \mathrm{O}_{3}$, and $\mathrm{CaO}$ ) on the SS plate before welding [2]. Particularly the $\mathrm{SiO}_{2}$ flux has shown an improved depth of penetration over $\mathrm{Cr}_{2} \mathrm{O}_{3}, \mathrm{TiO}_{2}$ and $\mathrm{CaO}$ on $316 \mathrm{~L}$ grade austenitic stainless steel [3]. This particular method is named as Activated flux Gas Tungsten Arc Welding (AGTAW). The improved depth of penetration through the AGTAW process is achieved by the following key phenomenon viz: (i) Arc constriction (ii) Reverse Marangoni convection. Joining of $10 \mathrm{~mm}$ thickness 304LN plate was done in a single pass using the AGTAW process whereas joining of the same plate took seven passes by the conventional GTAW process [4]. The SS welded joints are experiencing different types of load conditions during their services. This phenomenon leads to deformation in that particular zone of the base metal as well as welded joints.

The contactless Infrared Thermography (IRT) technique is taking a vital role in many engineering applications due to the accurate monitoring of temperature variations with fast inspection rates [5]. This is accomplished by the concept of Infrared radiations from a deforming material that is detected by the IR 
camera, and the radiations are converted into temperature patterns (or) thermograms. These temperature patterns are stored and analyzed using computer workstations. Deformation distribution in the material and its severity is clearly assessed by the intensity of the temperature patterns. Successful assessment of material deformation is carried out on metals, polymers and composite materials using the IRT technique [6,7]. Deformation study of St3S and S355J2G3 steel grades were evaluated using the IRT technique under static and dynamic loading conditions [8]. Many researchers successfully used the IRT technique to study the deformation behavior of steels and stainless steels and its weldments during the tensile test [9:13]. Also, failure locations can be predicted in advance through the IRT technique using thermograms. In this experimental investigation, the IRT technique has been used to study the influence of microstructural morphologies on the tensile deformation behavior of the nuclear grade austenitic stainless steel and its welded joints.

\section{Materials and Methods}

\section{Fabrication of Weld Joints}

Nuclear grade austenitic stainless steel 316LN was taken as Base Metal (BM) to study the tensile deformation behavior using the IR-Thermography technique. The chemical composition of 316LN austenitic stainless steel is given in table I. The base metal with a length of $300 \mathrm{~mm}$, a width of $75 \mathrm{~mm}$ and a thickness of $3 \mathrm{~mm}$ was prepared to make the weld joints. Edge preparation was completed using the $\mathrm{V}$ groove and square butt joint configuration for GTAW and AGTAW joints respectively. The filler material 316L which is having a similar chemical composition to the base metal was used for the fabrication of the GTAW joint. The chemical composition of the 316L filler metal is given in table I.

Table I. Chemical composition of the base metal and filler material

\begin{tabular}{cccccccccccc}
\hline \multirow{2}{*}{ Material } & \multicolumn{10}{c}{ Weight \% of elements } \\
\cline { 2 - 13 } & C & Cr & Ni & Mo & Mn & Si & S & P & N & Fe \\
\hline 316LN (BM) & 0.026 & 17.8 & 11.7 & 2.4 & 1.6 & 0.45 & 0.009 & 0.026 & 0.095 & Balance \\
\hline 316L (Filler) & 0.019 & 18.5 & 12.2 & 2.3 & 1.57 & 0.47 & 0.003 & 0.024 & - & Balance \\
\hline
\end{tabular}

A paste like component was made by dissolving multi-compound activated flux (combinations of $\left.\mathrm{Cr}_{2} \mathrm{O}_{3}(10 \div 20 \%), \mathrm{TiO}_{2}(30 \div 50 \%), \mathrm{SiO}_{2}(25 \div 40 \%), \mathrm{CuO}(5 \div 15 \%), \mathrm{NiO}(5 \div 15 \%)\right)$ in acetone [14]. This prepared paste form activated flux was applied to the square butt joint configuration before the fabrication process. Tungsten-2\% Thorium electrode was used for the fabrication of the GTAW and AGTAW processes. The argon gas with the purity level of $99.995 \%$ was used as shielding gas during the fabrication of welded joints. The process parameter used to fabricate weld joints is given in table II.

Table II. Process parameters used for welding processes

\begin{tabular}{|c|c|c|c|}
\hline \multirow[t]{2}{*}{ Name of the Parameter } & \multicolumn{2}{|c|}{ GTAW } & \multirow{2}{*}{ AGTAW } \\
\hline & Pass-1 & Pass-2 & \\
\hline Filler wire diameter (mm) & 2.4 & 2.4 & - \\
\hline Electrode diameter (mm) & 2 & 2 & 2 \\
\hline Tip angle & $60^{\circ}$ & $60^{\circ}$ & $60^{\circ}$ \\
\hline Welding current I (A) & 65 & 64 & 120 \\
\hline Arc voltage V (V) & 12 & 11 & 12.6 \\
\hline Welding speed S (mm/min) & 60 & 58 & 85 \\
\hline Shielding gas \& flow rate $(1 / \mathrm{min})$ & $\mathrm{Ar} / 10$ & $\mathrm{Ar} / 10$ & $\mathrm{Ar} / 10$ \\
\hline Heat input $Q(\mathrm{~kJ} / \mathrm{mm})$ & 0.78 & 0.79 & 1.067 \\
\hline
\end{tabular}

\section{Microstructure}

Metallographic samples of the base metal and welded joints (transverse side) were polished up to 3000 grit emery sheet. Further samples were polished using a $0.1 \mu \mathrm{m}$ diamond paste to eliminate microsized impurities. The etching process was done using a properly mixed solution named aquaregia (1:3 ratios of $\mathrm{HNO}_{3}$ to $\mathrm{HCl}$ ) as per ASTM standard designation E407 [15]. Microstructural morphologies of the base metal and weld zones of the GTAW and AGTAW joints were captured using an Olympus BX51M Optical Microscope. 


\section{Infrared Thermography}

Figure 1 depicts the experimental setup of IRT during the tensile deformation study. The tensile test of the base metal and welded joints were done using Dartec, UK, 100KN hydraulic servo motor computercontrolled Universal Testing Machine (UTM). The crosshead speed of $2 \mathrm{~mm} / \mathrm{min}$ was maintained during the tensile test. Thermographic images were recorded by IR camera CEDIP Silver 420 with $25 \mathrm{~m} /{ }^{\circ} \mathrm{C}$ temperature sensitivity. Figures $2 \mathrm{a}$ and $2 \mathrm{~b}$ depict the base metal and welded joints before and after the tensile deformation study. Spray paint of black color was uniformly applied backside of all tensile specimens to improve surface emissivity during the experiment (Fig. 2a).



Fig. 1. Experimental setup of IRT during the tensile test

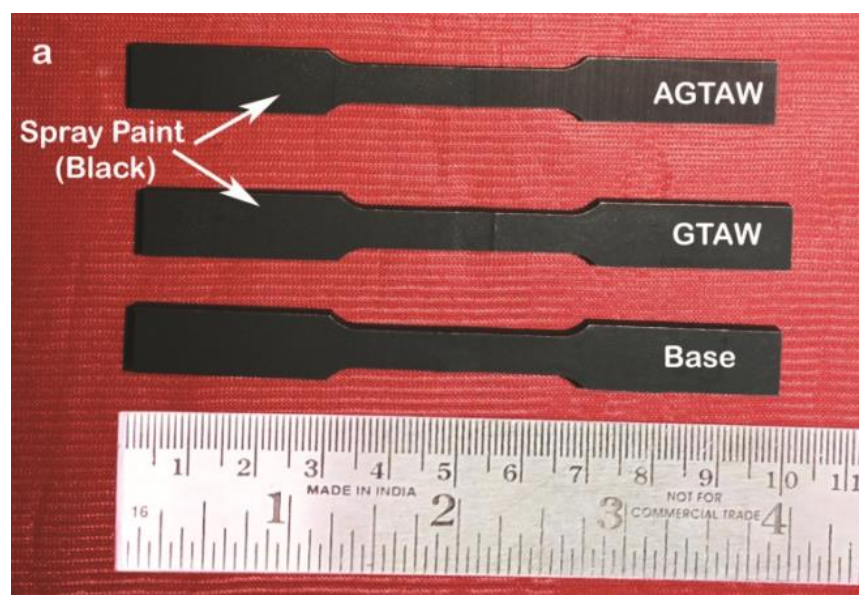

(a)

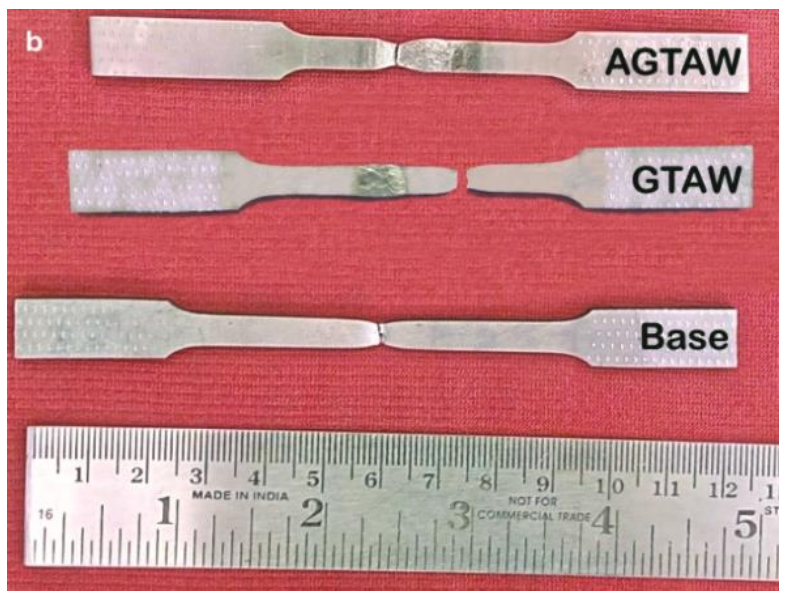

(b)

Fig. 2. Tensile Sample a) before the test b) after the test

\section{Results and discussion}

\section{Microstructure}

The base metal microstructure comprised a complete austenite phase. Annealing twins (parallel) was observed clearly inside the austenite matrix and it is shown in figure 3. These annealing twins are formed during the fabrication process of the 316LN base plate (Hot rolling). The FZ of the GTAW process exhibited little complex microstructural morphology is shown in Figure 4a. This is attributed to repeated thermal cycles and usage of filler material during the GTAW process. Both primary austenite (AF) and primary ferrite (FA) mode of solidification occurred at the FZ of the GTAW process [16]. The presence of ferrite promoting element $(\mathrm{Cr} \& \mathrm{Mo})$ in the filler material and fast cooling rate are predominant factors for the FA mode of solidification. A similar ferrite phase was identified on a 301L grade stainless steel fusion zone by Pulsed current TIG welding process [17]. Cellular structure and dendritic grain morphologies were observed at the center of the GTAW fusion zone. Adjacent to the cellular structure columnar grain growth 
was observed near to the fusion line (Fig. 4b). The center of the FZ and HAZ of the AGTAW process is shown in Figure 4c \& d respectively. AGTAW fusion zone comprised a distribution of equiaxed grains at the center. Adjacent sides of the equiaxed morphology, the presence of columnar structure was identified. Also, some dendrites were noticed in between columnar grain growth. The grain growth was noticed at the HAZ of the AGTAW joint due to the slow cooling nature of this particular process. Similar grain growth at HAZ was observed around $200 \mu \mathrm{m}$ size on austenitic stainless steel grade by the AGTAW process [18]. Also, the presence of $\delta$-ferrite in the form of stringers clearly noticed at the HAZ of the AGTAW joint (Fig. 4d). This is attributed to the segregation of the ferrite promoting element (mainly $\mathrm{Cr}$ ) at the HAZ during the solidification process.

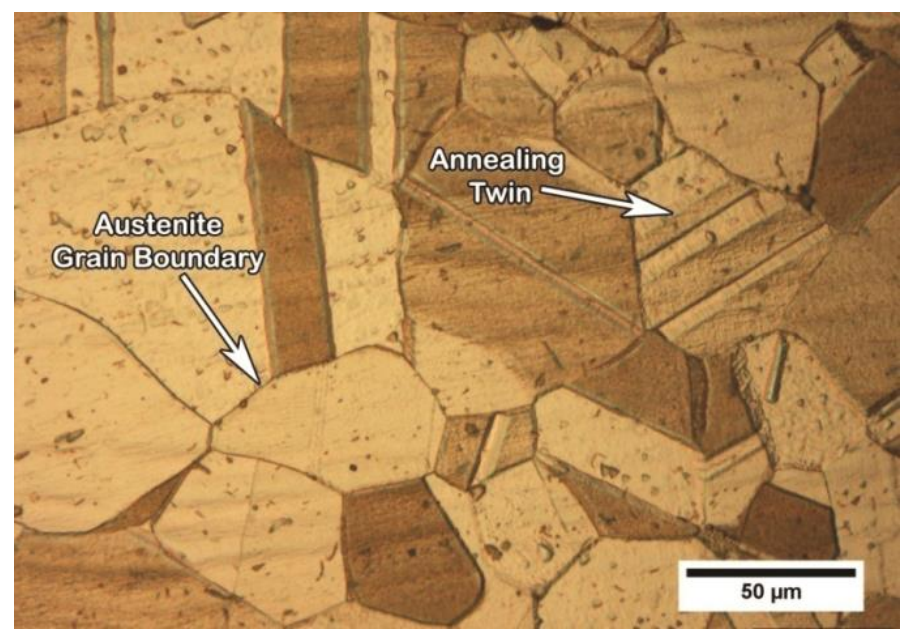

Fig. 3. Microstructure of 316LN Base Metal



(a)

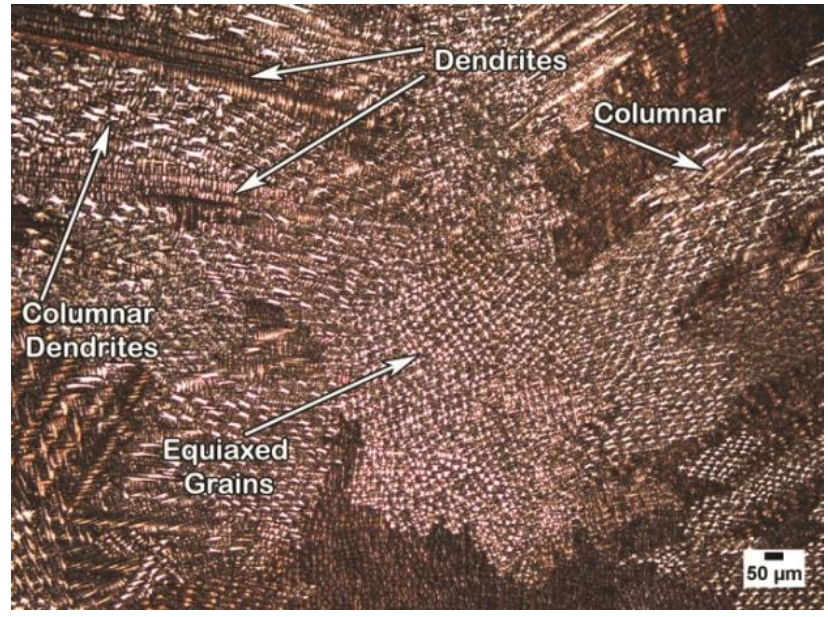

(c)

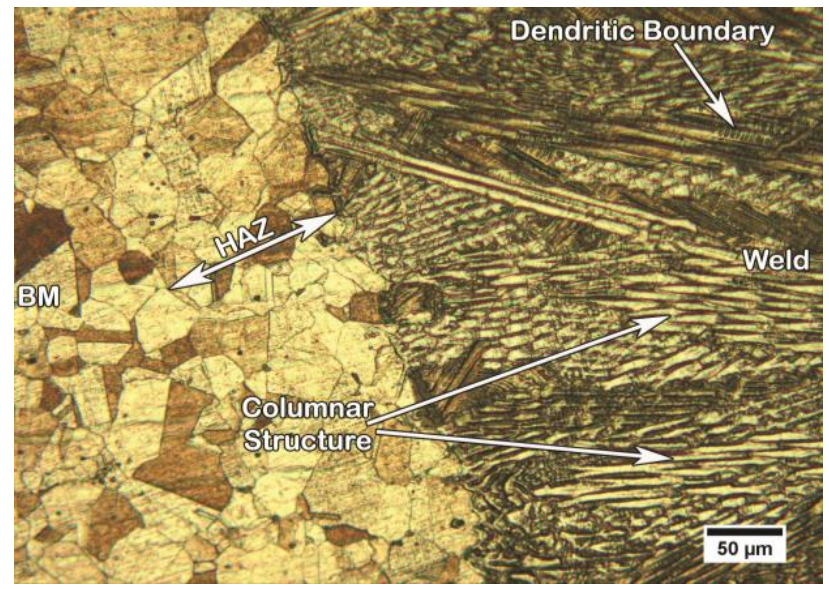

(b)

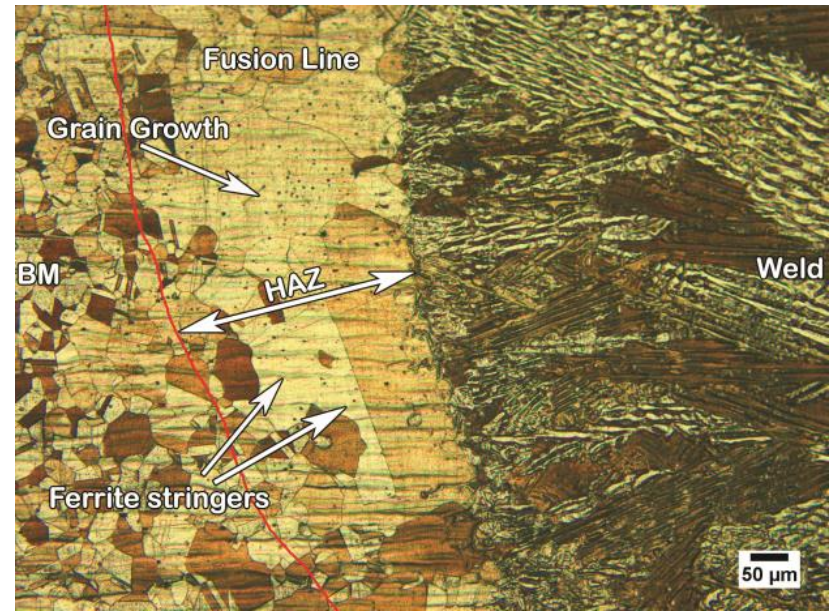

(d)

Fig. 4. Microstructural Morphologies: a) GTAW FZ b) GTAW HAZ c) AGTAW FZ d) AGTAW HAZ 


\section{Tensile properties}

For each welding and base metal, three samples were tested to evaluate tensile properties and the average values of Yield Strength (YS) and Ultimate Tensile Strength (UTS) are given in table III. The base metal sample failed at the center of the gauge portion. Whereas the failure of the GTAW and AGTAW sample occurred at the base metal side (away from the fusion line) and HAZ respectively. Grain growth at the HAZ of the AGTAW joint is the reason for the failure at this particular zone. GTAW sample has shown similar tensile results to the base metal since the failure occurred at the base metal side.

Table III. Tensile properties of the base metal and welded joints (transverse)

\begin{tabular}{cccccccc}
\hline S.No & $\begin{array}{c}\text { Sample } \\
\text { specification }\end{array}$ & $\begin{array}{c}\text { Crosshead } \\
\text { speed } \\
(\mathbf{m m} / \mathbf{m i n})\end{array}$ & $\begin{array}{c}\text { Strain } \\
\text { rate }\left(\mathbf{s}^{-1}\right)\end{array}$ & $\begin{array}{c}\text { YS } \\
(\mathbf{M P a})\end{array}$ & $\begin{array}{c}\text { UTS } \\
(\mathrm{MPa})\end{array}$ & $\begin{array}{c}\text { \% of } \\
\text { elongation }\end{array}$ & Failure location \\
\hline 1. & BM & 2 & $4.4 \times 10^{-4}$ & 319 & 616 & 64.14 & Center of the Gauge portion \\
2. & GTAW & 2 & $4.4 \times 10^{-4}$ & 311 & 609 & 52.8 & Base metal side \\
3. & AGTAW & 2 & $4.4 \times 10^{-4}$ & 298 & 601 & 49.2 & HAZ \\
\hline
\end{tabular}

\section{Evolution of temperatures}

Figure $5 a, 5 b$ and $5 c$ depicts the Thermographic images (thermograms) at different three stages during tensile deformation of the base metal, GTAW and AGTAW samples respectively. These thermograms are shown at different timings during the tensile testing. During the preferential stretching of samples at the gauge portions, the plastic zones are clearly observed and recorded in terms of thermograms (rose color in thermograms). Figure $5 a^{\prime}, 5 b^{\prime}$ and $5 c^{\prime}$ depicts plots for the evolution of temperature distribution along the axial length of the base metal, GTAW and AGTAW samples respectively. These temperature plots were made as a function of the given strain rate. The peak temperatures points of the base metal and welded joints were recorded just before to the time of fracture. There are $39.4{ }^{\circ} \mathrm{C}, 38.8^{\circ} \mathrm{C}$ and $34{ }^{\circ} \mathrm{C}$ for the base metal, GTAW and AGTAW samples respectively. These peak temperatures were identified exactly at the failure location of all samples using the axial temperature plots.

\section{Tensile behavior Vs peak temperature}

The evolution of peak temperature with respect to the time is described in the form of temperature curve and it is divided into four main stages based on the deformation behavior of any ductile material (Fig. 6). They are (I) Linear temperature drop stage (II) Temperature rise stage (III) Rapid temperature rise stage (IV) Final temperature decline stage $[19,20]$. At the stage-I temperature of the material drops in a linear manner due to the thermoelastic effect. This linear drop is continuing up to the yield point of the particular material. At stage-II, the temperature rises gradually due to the effect of plastic deformation [21]. The conversion of existing plastic energy to heat energy during the plastic deformation of the metal is the key reason for this phenomenon. At stage-III the temperature profile increases rapidly with respect to the time. This is attributed to the plastic deformation influenced by the strain energy of the initiated crack tip during necking. At the stage-IV temperature of the fractured surface drops suddenly due to the action of heat conduction.

Generally, tensile fracture of any ductile material happens by the following sequence: (i) formation of internal cavities due to plastic flow (ii) gradual growth of the internal cavities during plastic deformation (iii) eventually, fracture due to the coalescence of all cavities [22]. This sequence is strongly influenced by the grain size and microstructural morphology of the material which is undergoing the deformation.

During the tensile experiment, the linear temperature drop stage ends at $207 \mathrm{~s}$ for the base metal, $203 \mathrm{~s}$ for the GTAW joint and $163 \mathrm{~s}$ for the AGTAW joint. At the end of this stage, the particular weld joint/Base metal reaches the yield point. The lesser time duration of the AGTAW joint indicated that it experienced lesser stress compared to the base metal and GTAW joint at the initial stage since the strain rate was constant. In the second stage, temperature increase gradually with the effect of plastic deformation. This gradual temperature rise was recorded up to $1570 \mathrm{~s}$ for the base metal $888 \mathrm{~s}$ for the GTAW and $562 \mathrm{~s}$ for the AGTAW joint.

Just before the fracture, the base metal, GTAW and AGTAW samples exhibited peak temperatures of $39.4{ }^{\circ} \mathrm{C}$ after 1690 secs (Fig. 7a), $38.8^{\circ} \mathrm{C}$ after 930 secs (Fig. 8a) and $34{ }^{\circ} \mathrm{C}$ after 570 secs (Fig. 7a) respectively. The peak temperature of the GTAW sample very near to the base metal peak temperature value since it failed at the base metal side away from the fusion line. Meantime the lesser time for the failure of the 
GTAW sample compared to the base metal is attributed to the existence of refined grains (fusion zone) at the gauge portion. Failure of the AGTAW sample occurred at the HAZ with the lesser peak temperature value and failure time compared to the base metal and GTAW sample. This is indicating that the weld zone (HAZ) of the AGTAW joint undergone lesser deformation compared to the base metal.

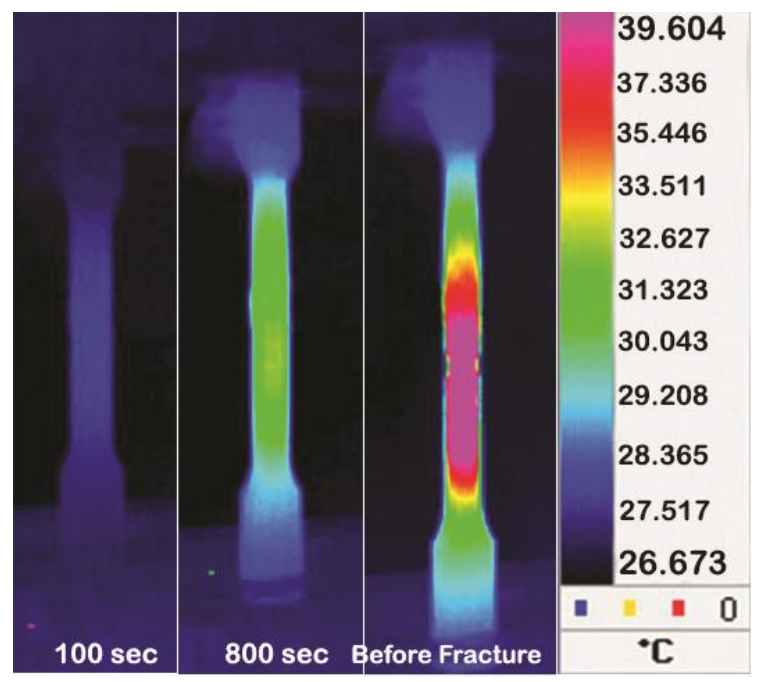

(a)

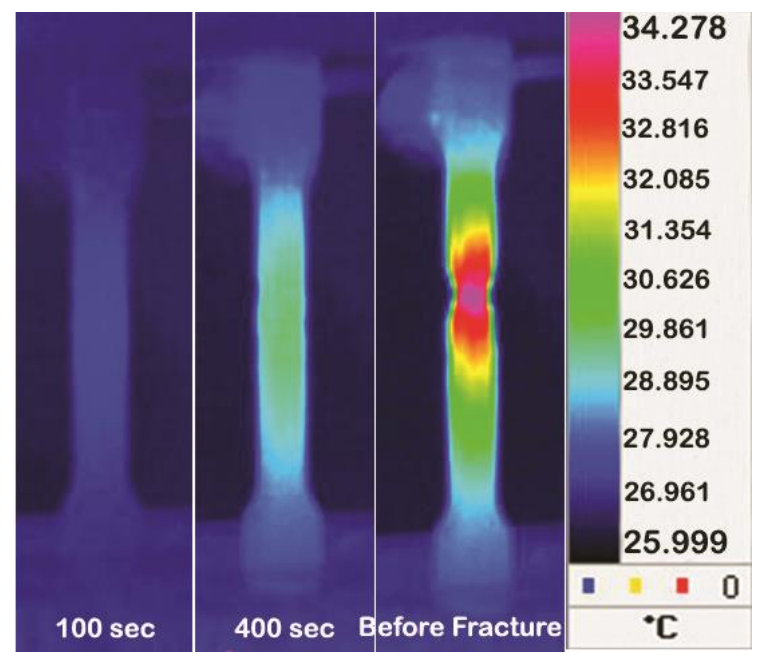

(b)



(c)

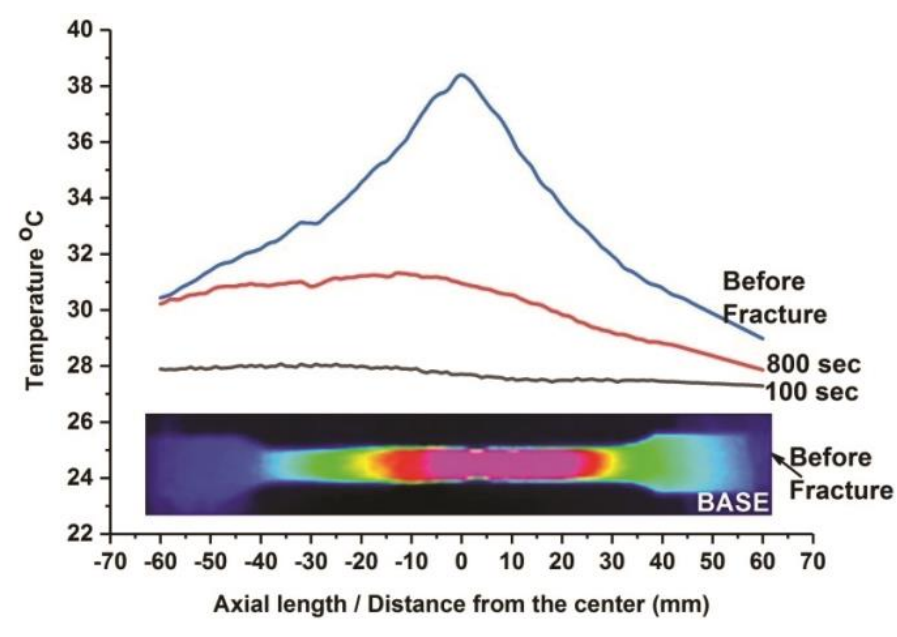

(a')

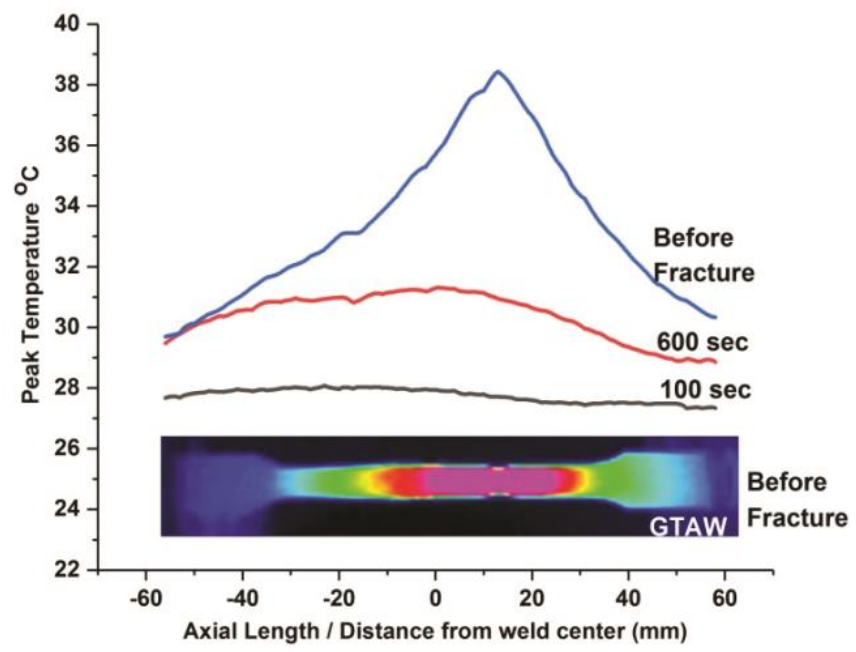

(b')



$\left(c^{\prime}\right)$

Fig. 5. Thermographic Images of a) the base metal, b) GTAW and c) AGTAW samples. Evolution of temperatures in axial length of a') base metal, b') GTAW and c') AGTAW samples 


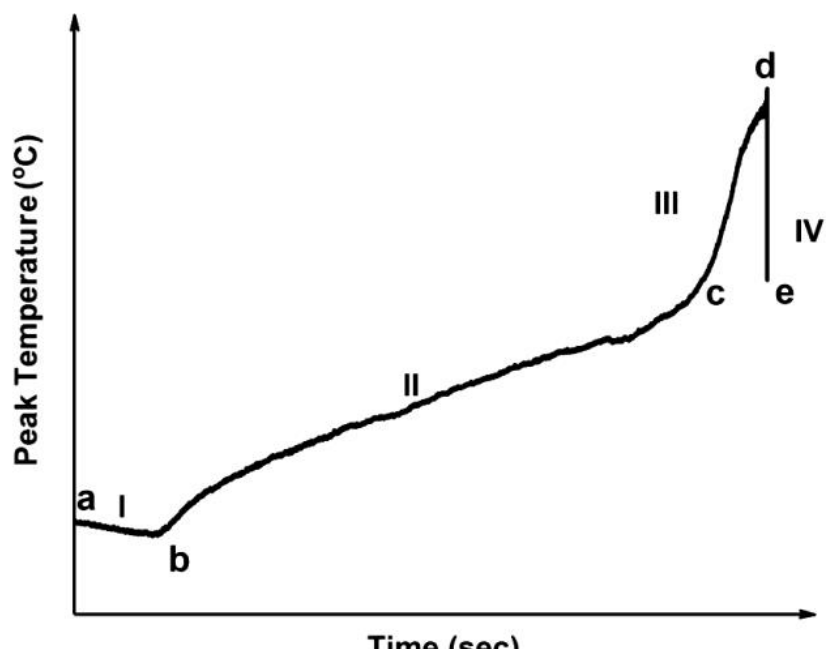

Time (sec)

Fig. 6. Standard Temperature Curve (Evolution of peak temperature)

Thermograms of the tensile failure sequence for the base metal, GTAW and AGTAW samples are correlated with corresponding tensile behavior and shown in Figures $7 \mathrm{~b}, 8 \mathrm{~b}$ and $9 \mathrm{~b}$ respectively. Severe plastic deformation was clearly seen at the stage-III (during necking) using thermograms and this phenomenon is matching with the third stage of temperature curve by sudden temperature rise.



(a)

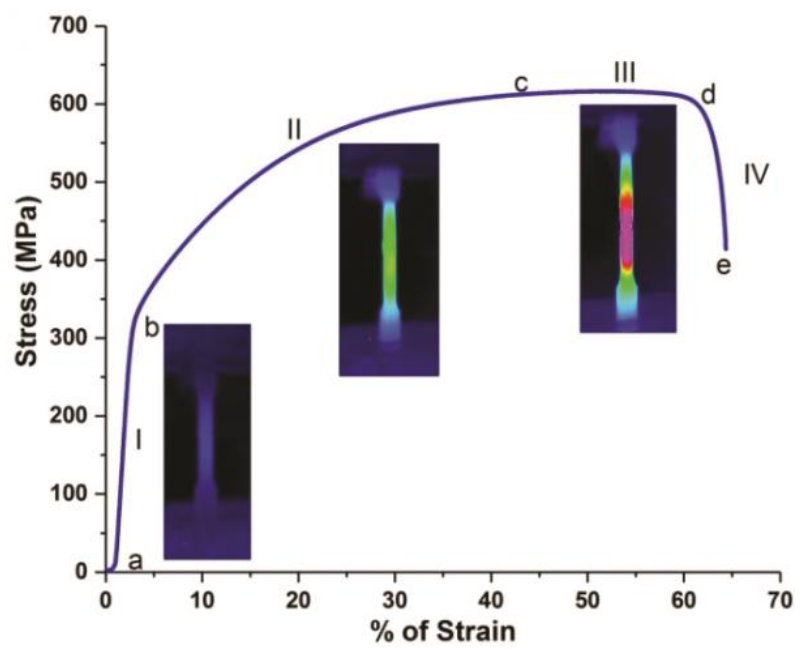

(b)

Fig. 7. a) Evolution of peak temperature of the base metal during deformation with respect to time, b) Stress Vs Strain curve of base metal

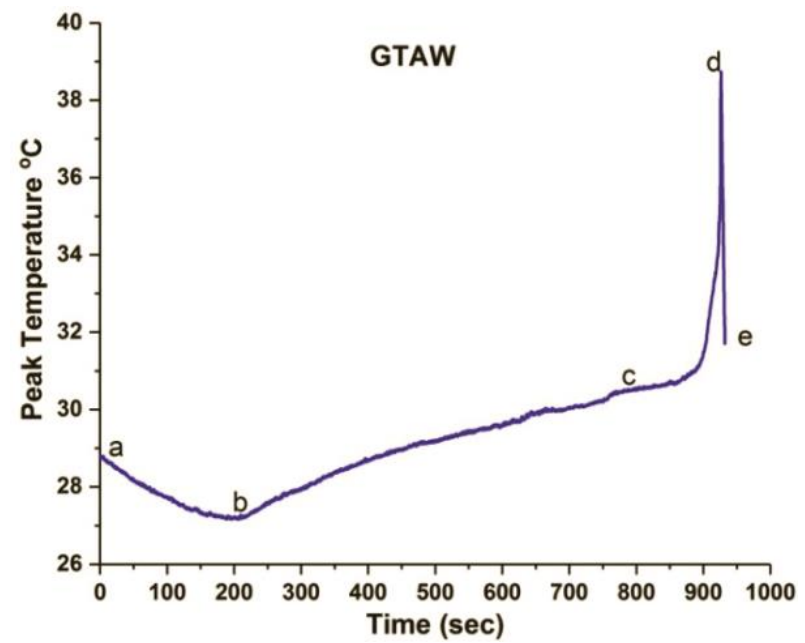

(a)

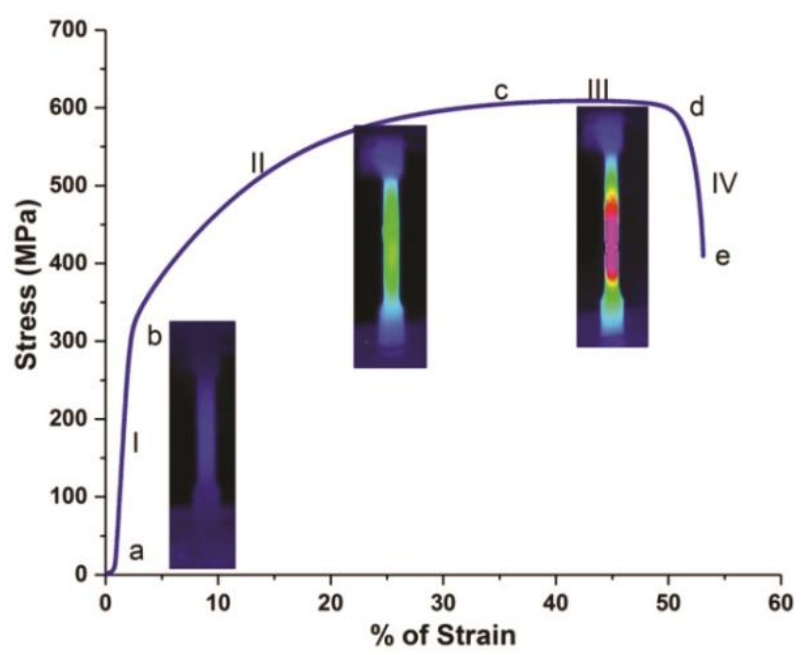

(b)

Fig. 8. a) Evolution of peak temperature in GTAW sample during deformation with respect to time, b) Stress Vs Strain curve for GTAW sample 


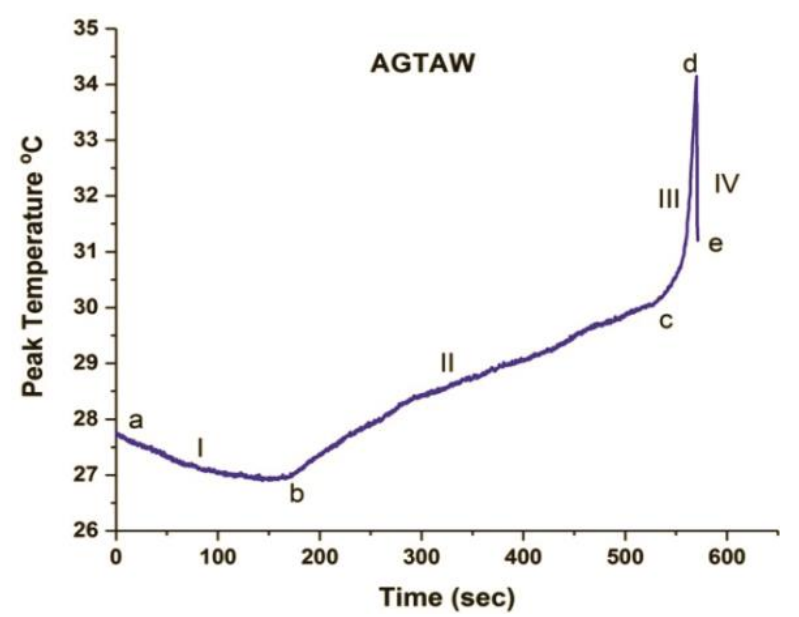

(a)

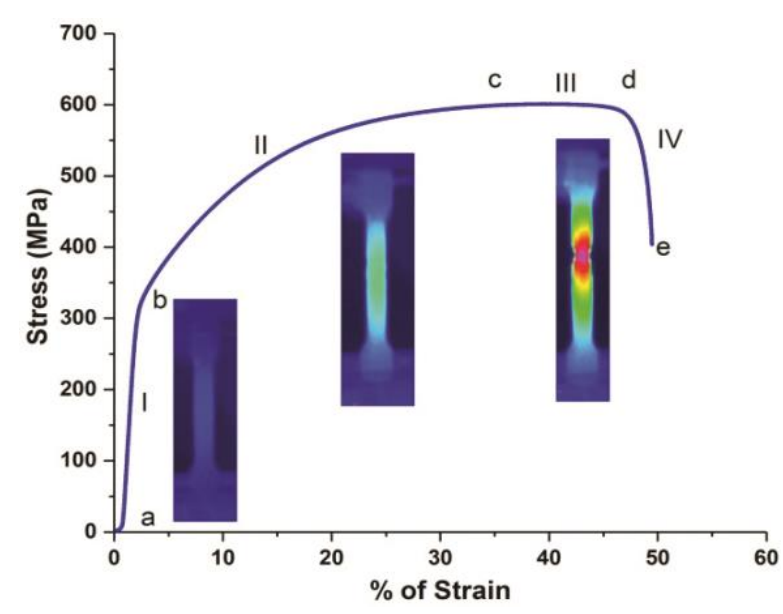

(b)

Fig. 9. a) Evolution of peak temperature in AGTAW sample during deformation with respect to time, b) Stress Vs Strain curve for AGTAW sample

\section{Conclusions}

The following conclusions are derived regarding the correlation between tensile deformation behavior and microstructural morphology of nuclear grade austenitic stainless steel welded joints using infrared thermography technique.

- During the transverse tensile test, GTAW samples failed at the base metal side away from the fusion line and showed similar tensile properties to the base metal. AGTAW sample failed at HAZ and showed the inferior tensile property as compared to the base metal and GTAW sample.

- During the tensile deformation study, peak temperatures were recorded just before the time of fracture for the base metal and welded joints. This phenomenon is attributed to the conversion of available plastic energy into the heat energy at the severe plastic deformation zone. Moreover, failure locations were revealed in terms of temperature patterns in advance before the occurrence of fracture during the tensile test.

- From IR-Thermography images, peak temperatures of $39.4{ }^{\circ} \mathrm{C}, 38.8^{\circ} \mathrm{C}$ and $34{ }^{\circ} \mathrm{C}$ were observed at the base metal, GTAW and AGTAW samples. The GTAW joint shown similar results to the base metal since it has failed at the base metal side. But the AGTAW joint shown around $14 \%$ lesser peak temperature as compared to the base metal and the failure was recorded at HAZ. This result indicating that the HAZ of the AGTAW joint has undergone lesser deformation as compared to the base metal.

Author Contributions: conceptualization R. R., A. K. L.; methodology R. R.; software M. M.; validation R. R., A. K. L.; formal analysis R. R.; investigation R. R., M. M.; resources A. K. L., M. M.; writing-original draft preparation R. R.; writing R. R.; review and editing R. R.; A. K. L.; supervision: A. K. L.; project administration A. K. L.

Funding: This research received no external funding.

Acknowledgments: The authors are grateful to Director of Indira Gandhi Centre for Atomic Research (IGCAR) for permitting us to use the IR thermography facility.

Conflicts of Interest: The authors declare no conflict of interest. The funders had no role in the design of the study; in the collection, analyses, or interpretation of data; in the writing of the manuscript, or in the decision to publish the results.

\section{References}

[1] Mannan SL., Chetal S., Selection of materials for prototype fast breeder reactor, Transactions of the Indian Institute of Metals, 2003, Vol. 56(2), 155-178.

[2] Kuang H.T., Chih Y.H., Performance of activated TIG process in austenitic stainless steel welds, Journal of Materials Processing Technology, 2011, Vol. 211, 503-512. https://doi.org/10.1016/j.jmatprotec.2010.11.003

[3] Ahmadi E., Ebrahimi A.R., Welding of 316L Austenitic Stainless Steel with Activated Tungsten Inert Gas Process, Journal of Materials Engineering and Performance, 2015, Vol. 24, 1065-1071. https://doi.org/10.1007/s11665-014-1336-6 
[4] Vasudevan M., Effect of A-TIG Welding Process on the Weld Attributes of Type 304LN and 316LN Stainless Steels, Journal of Materials Engineering and Performance, 2017, Vol. 26(3), 1325-1336. https://doi.org/10.1007/s11665017-2517-x

[5] Bagavathiappan S., Lahiri B.B., Saravanan T., John P., Jayakumar T., Infrared thermography for condition monitoring - A review, Infrared Physics and Technology, 2013, Vol. 60, 35-55. https://doi.org/10.1016/j.infrared.2013.03.006

[6] Sony P., Amretendu M., Rajdeep S., Zafir A., Dipak D, Vikas K., Determination of critical strain for rapid crack growth during tensile deformation in aluminide coated near- $\alpha$ titanium alloy using infrared thermography, Materials Science and Engineering A, 2013, Vol. 576, 217-221. https://doi.org/10.1016/j.msea.2013.03.089

[7] Górka J., Janicki D., Fidali M., Jamrozik W., Thermographic Assessment of the HAZ Properties and Structure of Thermomechanically Treated Steel, International Journal of Thermophysics, 2017, Vol. 38(183), 1-21. https://doi.org/10.1007/s10765-017-2320-9

[8] Psuj G., Szymanik B., Łopato P., Herbko M., Maciusowicz M., Multimodal monitoring of damage in steel construction elements during fatigue life, Welding Technology Review, 2016, Vol. 88(10), $104-109$. https://doi.org/10.26628/ps.v88i10.695

[9] Haneef T., Lahiri BB., Bagavathiappan S., Mukhopadhyay CK., Philip J., Rao BP., Jayakumar T., Study of the tensile behavior of AISI type 316 stainless steel using acoustic emission and infrared thermography techniques, Journal of Materials Research and Technology, 2015, Vol. 4(3), 241-53. https://doi.org/10.1016/j.jmrt.2014.12.008

[10] Corigliano P., Crupi V., Epasto G., Guglielmino E., Risitano G., Fatigue assessment by thermal analysis during tensile tests on steel, Procedia Engineering, 2015, Vol. 109, 210-218. https://doi.org/10.1016/j.proeng.2015.06.215

[11] Corigliano P., Cucinotta F., Guglielmino E., Risitano G., Santonocito D., Thermographic analysis during tensile tests and fatigue assessment of S355 steel, Procedia Structural Integrity, 2019, Vol. 18, $280-286$. https://doi.org/10.1016/j.prostr.2019.08.165

[12] Pawlak S., Różański M., Muzia G., The application of active Thermography for non-destructive testing of brazed joints, Welding Technology Review, 2014, Vol. 85(2), 24-28. https://doi.org/10.26628/ps.v85i2.276

[13] Pawlak S., Różański M., Stano S., Muzia G., Active Thermography as a new method of testing non-destructive laser welded lap joints, Welding Technology Review, 2014 , Vol. 86(3), 4-7. https://doi.org/10.26628/ps.v86i3.100

[14] Vasudevan M., Bhaduri AK., Baldev R., Penetration enhancing flux formulation for tungsten inert gas (TIG) welding of austenitic stainless steel and its application, US8097826B2.

https://patents.google.com/patent/US8097826B2/en [Hyperlink]

[15] ASTM Designation: E 407 - 07: (2015) e1. Standard Practice for Microetching Metals and Alloys. https://www.astm.org/Standards/E407 [ Hyperlink]

[16] Rajasekaran R., Lakshminarayanan A.K., Vasudevan M., Vasantharaja P., Role of welding processes on microstructure and mechanical properties of nuclear grade stainless steel joints, Proceedings of the Institution of Mechanical Engineers, Part L: Journal of Materials: Design and Applications, 2019, Vol. 233(11). https://doi.org/10.1177\%2F1464420719849448

[17] Ostromęcka M., Kolasa A., The effect of the current pulsation frequency on heat supply results during pulsed current TIG welding in 301L stainless steel, Welding Technology Review, 2019, Vol. 91(8), 61-71. https://doi.org/10.26628/wtr.v91i8.1046

[18] Vijayanand V.D., Vasudevan M., Ganesan V., Parameswaran P., Laha K., Bhaduri A.K., Creep deformation and rupture behavior of single-and dual-pass 316LN stainless-steel-activated TIG weld joints, Metallurgical and Materials Transactions A, 2016, Vol. 47(6), 2804-2814. https://doi.org/10.1007/s11661-016-3426-6

[19] Yan Z., Zhang H., Chen P., Wang W., Anisotropy of fatigue behavior and tensile behavior of 5A06 aluminum alloy based on infrared thermography, Journal of Wuhan University of Technology Materials Science Edition, 2017, Vol. 32(1), 155-161. https://doi.org/10.1007/s11595-017-1574-1

[20] Kumar J., Baby S., Kumar V., Thermographic studies on IMI-834 titanium alloy during tensile loading, Materials Science and Engineering: A, 2008, Vol. 496, 303-307. https://doi.org/10.1016/j.msea.2008.05.040

[21] Kutin M., Ristić S., Burzić Z., Puharić M., Testing the tensile features of steel specimens by thermography and conventional methods, Scientific Technical Review, 2010, Vol. 60(1), 66-70. http://www.vti.mod.gov.rs/ntp/rad2010/1-10/9/e9.htm; [Hyperlink]

[22] Venkatraman B., Mukhophadyay C.K., Raj B., Prediction of tensile failure of 316 stainless steel using infrared thermography, Experimental Techniques, 2004, Vol. 28(2), 35-38. https://doi.org/10.1111/j.1747-1567.2004.tb00157.x

(C) 2020 by the authors. Submitted for possible open access publication under the terms and conditions of the Creative Commons Attribution (CC BY) license (http://creativecommons.org/licenses/by/4.0/). 